\title{
ОПЫТ СОСТАВЛЕНИЯ ШКАЛ ТРУДНОСТИ ШКОЛЬНЫХ УРОКОВ НА ОСНОВАНИИ СУБЪЕКТИВНЫХ ОЦЕНОК УЧАЩИХСЯ
}

\author{
Максимов О.Л. ${ }^{1}$, Машдиева М.С. ${ }^{1}$, Квасов А.P. ${ }^{1}$, Аветисян 3.Е. ${ }^{1}$ \\ ${ }^{1}$ ФББОУ ВО «Ростовский государственный медицинский университет» Минздрава РФ, Ростов-на-Дону, е- \\ mail: Horek1999@yandex.ru \\ Для определения трудности учебных предметов в школе были обследованы 1633 учащихся трех \\ возрастных ступеней, которые с помощью цветового теста отношений (ЦО) обозначили свое отношение \\ к учебным предметам, преподаваемым в школе, а также дали «прямую» балльную оценку их трудности \\ и интереса к ним. Для обоснования взаимосвязи этих оценок с уровнем психофизиологического \\ напряжения организма школьников в период обучения у них исследовались показатели школьной \\ тревожности по тесту Филлипса и изучалась их корреляция с показателями субъективного отношения к \\ учебным предметам, а также с оценками трудности и интереса к уроку. Результаты выявили прямые \\ корреляции степени проявлений школьной тревожности с показателями балльных оценок тревожности \\ и субъективного отношения школьников к учебным предметам и обратные корреляции с уровнем \\ интереса к этим предметам. Проведенные исследования позволили определить «формулу» определения \\ трудности уроков по субъективным оценкам и предложить новую шкалу трудности основных учебных \\ предметов для каждого из 1-11-х классов, в целом не противоречащую действующим шкалам, но более \\ адекватно отражающую трудность учебных предметов в восприятии учащихся.
}

Ключевые слова: школьники, трудность учебных предметов, субъективное отношение, школьная тревожность, шкала трудности уроков.

\section{EXPERIENCE IN THE PREPARATION OF THE SCALE OF DIFFICULTY OF SCHOOL SUBJECTS ON THE BASIS OF SUBJECTIVE EVALUATIONS OF PUPILS}

\author{
Maximov O.L. ${ }^{1}$, Mashdieva M.S. ${ }^{1}$, Kvasov A.R. ${ }^{1}$, Avetisyan Z.E. ${ }^{1}$ \\ ${ }^{1}$ FSBEI HE «The Rostov State Medical University» of the Ministry of Healthcare of the Russian Federation, Rostov-on- \\ Don, e-mail: Horek1999@yandex.ru
}

1633 students of 3 age levels were examined for determination of the difficulty of subjects in school. They outlined their attitude to the subjects taught at school with the help of the color test of relations (CTR) and gave a "direct" score assessment of their difficulties and interest in them. The indicators of school anxiety on the Phillips test were studied in order to substantiate the relationship of the score assessments with the level of psychophysiological stress of the organism of pupils within the course of studies; studied correlation of school anxiety with indicators of subjective attitude to academic subjects, as well as assessments of difficulty and interest in the lesson. The results revealed direct correlations of the degree of school anxiety manifestations with the indicators of anxiety scores and subjective attitude of schoolchildren to academic subjects and inverse correlations with the level of interest in these subjects. The conducted research allowed to determine the "formula" for determining the difficulty of the lessons according to subjective evaluations and to propose a new scale challenges the basic academic subjects for each of 1-11 classes, in general, not contrary to the existing scales, but more appropriately reflecting the difficulty of the subjects in the perception of pupils.

Keywords: pupils, difficulty of subjects, subjective attitude, school-based anxiety, scale of difficulty of subjects.

Известно, что классическим подходом в оценке трудности новых учебных предметов остается сравнительный анализ динамики умственной работоспособности учащихся на уроках разных дисциплин [1;2]. Однако в реальности организация единых условий для проведения естественного гигиенического эксперимента весьма сложна из-за необходимости учета многих сопутствующих факторов [3]: это проблема объективного сопоставления сложности разных по содержанию предметов, обеспечение одинакового уровня преподавания разными учителями, учет плотности уроков и «кумуляции» предыдущих 
нагрузок, изменяющих функциональное состояние самих учащихся, применение физкультпауз и электронных средств обучения и прочее $[1 ; 4 ; 5]$. Сочетание этих факторов может существенно меняться на каждом уроке по любому предмету в течение учебного дня, недели, четверти и года. При этом кратные различия в оценке трудности «самых трудных» и «легких» предметов в действующих ранговых шкалах $[2 ; 6 ; 7]$ представляются не вполне обоснованными. Вот почему проблема оценки трудности учебных предметов и поиск новых подходов к ее оценке остается достаточно актуальной в условиях многообразия школьных программ и либерализации систем и приемов школьного обучения.

Цель исследования - дать гигиеническое обоснование построению шкал трудности школьных предметов на основании субъективных оценок учащихся.

Материалы и методы исследования. С 2009 по 2014 г. в ходе различных исследований, проводившихся на кафедре гигиены РостГМУ среди учащихся 1-11-х классов из 6 средних общеобразовательных учреждений Юга России, были получены данные о субъективном отношении 1633 учащихся к основным преподаваемым школьным предметам. В исследовании приняли участие 610 учащихся 1-4-х классов, 830 - 5-8-х классов и 193 учащихся 9-11-х классов; по половому составу 805 мальчика и 828 девочек составили общее гендерное соотношение как 49,3\% и 50,7\%. Исследования субъективного отношения учащихся к школьным предметам проводились с помощью цветового теста отношений (ЦТО) [8]: с помощью 8 цветов теста Люшера через цветовые ассоциации учащимися ранжировались учебные предметы в соответствии с их субъективной оценкой собственными «шкалами ценностей и приоритетов». Обозначенное цветом отношение школьников к отдельным учебным предметам, а также отношение ко всем предметам в школе переводилось в балльные оценки, соответствующие нормативным значениям цвета в тесте Люшера и его рангу в шкале индивидуальных цветовых приоритетов; сумма этих оценок определяла итоговую балльную оценку субъективного отношения к предмету. Чем меньше каждая из оценок, тем выше (благоприятнее) субъективная оценка предмета, и наоборот. Кроме этого, те же уроки еще и «прямо» оценивались по степени трудности по пятибалльной шкале (от самого легкого до самого трудного предмета - от 1 до 5) и по степени интереса к ним (от самого неинтересного, скучного до самого интересного - от 1 до 5). Для гигиенического обоснования возможности использования этих показателей для оценки трудности школьных предметов исследовались их корреляционные взаимосвязи с показателями школьной тревожности, 8 показателей которой определялись у тех же школьников по тесту Филлипса [9]; для корреляционного анализа были отобраны результаты школьной тревожности 1306 учащихся.

Статистический анализ полученных данных проводился в программе Statistica 6.0 в 
модуле «Основные статистики» с уровнем значимости статистической ошибки $\mathrm{p}<0,05$.

Результаты. В таблице 1 представлен пример регистрации субъективного отношения одного и того же учащегося 2-го класса 1-й ступени (Н-ской школы) к русскому (родному) языку и математике, а также ко всем школьным урокам в целом (по ЦТО) и «прямых» оценок трудности и интереса к этим объектам.

Таблица 1

Пример показателей субъективной оценки отношения к учебным предметам, их трудности и интереса к ним у учащейся 2-го класса Виктории Е

\begin{tabular}{|c|c|c|c|c|c|}
\hline \multirow{2}{*}{ Учебные предметы } & \multicolumn{3}{|c|}{$\begin{array}{c}\text { Отношение к предмету } \\
\text { по ЦТО }\end{array}$} & \multirow[b]{2}{*}{$\begin{array}{c}\text { Трудность } \\
\text { урока }\end{array}$} & \multirow[b]{2}{*}{$\begin{array}{r}\text { Интерес } \\
\text { к уроку }\end{array}$} \\
\hline & цвет & ранг & $\begin{array}{l}\text { сумма } \\
\text { баллов } \\
\end{array}$ & & \\
\hline Русский (родной) язык & 4 & 2 & 6 & 1 & 5 \\
\hline Математика & 1 & 7 & 8 & 4 & 3 \\
\hline $\begin{array}{l}\text { Общее отношение к } \\
\text { учебным предметам }\end{array}$ & 4 & 2 & 6 & 5 & 2 \\
\hline
\end{tabular}

Данные Виктории Е. свидетельствуют о том, что отношение к урокам русского языка девочка обозначила желтым цветом (нормативное значение в тесте Люшера - 4), в ряду ее индивидуальных цветовых предпочтений желтый цвет стоит на втором месте (ранг - 2) и суммарная субъективная подсознательная оценка этого предмета для нее составила 6 баллов. «Прямые» оценки Викторией Е. трудности этого урока - 1 балл (минимальная), а интереса к уроку - 5 баллов (максимальная). Субъективное отношение Виктории Е. к урокам математики обозначено синим цветом (нормативное значение 1), его ранг - предпоследнее (7-е) место в ряду ее индивидуальных цветовых предпочтений, и потому общая сумма баллов субъективной оценки - 8. «Прямые» оценки трудности уроков математики - 4 балла, а интереса к ним - 3 балла. Ниже представлены показатели субъективного отношения по ЦТО ко всем урокам в школе (желтый цвет, 2-е ранговое место, сумма баллов - 6), а также «прямые» оценки трудности (5 - максимальная трудность) и интереса (2 - низкий интерес).

В таблице 2 представлены коэффициенты корреляции показателей субъективной оценки отношения ко всем учебным предметам в школе в целом, их трудности и интереса к ним с показателями школьной тревожности учащихся разных возрастных ступеней.

Таблица 2

Взаимосвязь показателей субъективной оценки отношения к учебным предметам, их трудности и интереса к ним с показателями школьной тревожности (представлены показатели с достоверными коэффициентами корреляции) 


\begin{tabular}{|c|c|c|c|c|c|}
\hline \multirow[t]{2}{*}{$\begin{array}{c}\text { Показатели школьной } \\
\text { тревожности }\end{array}$} & \multicolumn{3}{|c|}{$\begin{array}{c}\text { Отношение к школьным } \\
\text { предметам по ЦТО }\end{array}$} & \multirow{2}{*}{$\begin{array}{c}\text { Общая } \\
\text { трудность } \\
\text { уроков }\end{array}$} & \multirow{2}{*}{$\begin{array}{c}\text { Общий } \\
\text { интерес } \\
\text { к урокам }\end{array}$} \\
\hline & цвет & $\begin{array}{c}\text { ранг } \\
\text { цвета }\end{array}$ & $\begin{array}{l}\text { сумма } \\
\text { баллов } \\
\end{array}$ & & \\
\hline \multicolumn{6}{|c|}{ І. Данные учащихся 1-4-x классов $(n=414)$} \\
\hline Общая тревожность в школе & 0,07 & 0,00 & 0,04 & $0,28 *$ & $-0,09$ \\
\hline Переживание социального стресса & 0,07 & 0,04 & 0,04 & $0,12 *$ & $-0,08$ \\
\hline $\begin{array}{l}\text { Фрустрация потребности в } \\
\text { достижении успеха }\end{array}$ & 0,09 & $\mathbf{0 , 1 1 *}$ & 0,09 & $\mathbf{0 , 1 7 *}$ & $-0,14 *$ \\
\hline Страх самовыражения & $-0,07$ & $-0,05$ & $-0,06$ & $0,19 *$ & 0,03 \\
\hline Страх ситуации проверки знаний & 0,07 & $-0,02$ & 0,03 & $0,26 *$ & $-0,07$ \\
\hline $\begin{array}{l}\text { Страх не соответствовать } \\
\text { ожиданиям окружающих }\end{array}$ & 0,04 & 0,03 & 0,04 & $\mathbf{0 , 2 3 *}$ & $-0,21 *$ \\
\hline $\begin{array}{l}\text { Низкая физиологическая } \\
\text { сопротивляемость стрессу }\end{array}$ & $-0,01$ & $-0,02$ & $-0,02$ & $\mathbf{0 , 2 0 *}$ & $-0,07$ \\
\hline $\begin{array}{l}\text { Проблемы и страхи в отношениях } \\
\text { с учителями }\end{array}$ & 0,05 & $-0,05$ & $-0,02$ & $\mathbf{0 , 1 1 *}$ & $-0,12 *$ \\
\hline \multicolumn{6}{|c|}{ II. Данные учащихся 5-8-х классов $(n=714)$} \\
\hline Общая тревожность в школе & 0,02 & 0,07 & 0,06 & $0,10 *$ & $-0,06$ \\
\hline Переживание социального стресса & $\mathbf{0 , 1 1 *}$ & $\mathbf{0 , 1 0 *}$ & $0,12 *$ & $0,10 *$ & $-\mathbf{0 , 1 1 *}$ \\
\hline $\begin{array}{l}\text { Фрустрация потребности в } \\
\text { достижении успеха }\end{array}$ & $\mathbf{0 , 1 1 *}$ & $\mathbf{0 , 1 1 *}$ & $0,13 *$ & $0,11 *$ & $-0,10 *$ \\
\hline $\begin{array}{l}\text { Страх не соответствовать } \\
\text { ожиданиям окружающих }\end{array}$ & $0,12 *$ & $\mathbf{0 , 1 1 *}$ & $\mathbf{0 , 1 4 *}$ & $\mathbf{0 , 1 8 *}$ & $-0,14 *$ \\
\hline $\begin{array}{l}\text { Проблемы и страхи в отношениях } \\
\text { с учителями }\end{array}$ & 0,07 & 0,06 & $\mathbf{0 , 1 0 *}$ & $0,11 *$ & $-0,12 *$ \\
\hline \multicolumn{6}{|c|}{ III. Данные учащихся 9-11-х классов $(n=178)$} \\
\hline Общая тревожность в школе & 0,02 & 0,06 & 0,05 & $\mathbf{0 , 1 9 *}$ & $-0,02$ \\
\hline $\begin{array}{l}\text { Фрустрация потребности в } \\
\text { достижении успеха }\end{array}$ & 0,11 & $0,16 *$ & $\mathbf{0 , 1 7 *}$ & $0,21 *$ & $-0,11$ \\
\hline Страх самовыражения & 0,06 & 0,13 & 0,12 & $\mathbf{0 , 1 5 *}$ & 0,02 \\
\hline $\begin{array}{l}\text { Страх не соответствовать } \\
\text { ожиданиям окружающих }\end{array}$ & 0,06 & 0,13 & 0,12 & $0,15 *$ & $-0,06$ \\
\hline $\begin{array}{l}\text { Проблемы и страхи в отношениях } \\
\text { с учителями }\end{array}$ & 0,01 & 0,13 & 0,08 & $0,22 *$ & $-0,05$ \\
\hline \multicolumn{6}{|c|}{ Данные учащихся 1-11-х классов (n=1306) } \\
\hline Общая тревожность в школе & 0,04 & 0,05 & $\mathbf{0 , 1 0 *}$ & $\mathbf{0 , 1 8 *}$ & $-0,11 *$ \\
\hline Переживание социального стресса & $0,10 *$ & 0,11* & $0,12 *$ & $\mathbf{0 , 1 0 *}$ & $-0,12 *$ \\
\hline $\begin{array}{l}\text { Фрустрация потребности в } \\
\text { достижении успеха }\end{array}$ & $0,11 *$ & $0,12 *$ & $0,13 *$ & $0,11 *$ & $-0,10 *$ \\
\hline Страх самовыражения & 0,01 & 0,02 & 0,02 & $0,12 *$ & 0,00 \\
\hline Страх ситуации проверки знаний & 0,01 & $-0,00$ & 0,01 & $0,14 *$ & 0,00 \\
\hline $\begin{array}{l}\text { Страх не соответствовать } \\
\text { ожиданиям окружающих }\end{array}$ & $0,11 *$ & $\mathbf{0 , 1 1 *}$ & $0,13 *$ & $0,20 *$ & $-0,15 *$ \\
\hline $\begin{array}{l}\text { Низкая физиологическая } \\
\text { сопротивляемость стрессу }\end{array}$ & 0,01 & 0,02 & 0,02 & $0,10 *$ & $-0,03$ \\
\hline $\begin{array}{l}\text { Проблемы и страхи в отношениях } \\
\text { с учителями }\end{array}$ & $0,11 *$ & 0,04 & $0,10 *$ & $0,13 *$ & $-0,10 *$ \\
\hline
\end{tabular}

* - статистически достоверные коэффициенты корреляции $(\mathrm{p}<0,05)$. 
прямой связи слабой силы показателей школьной тревожности $\mathrm{c}$ показателями субъективного отношения учащихся к содержанию школьных предметов и их трудности (от $\mathrm{r}=0,10$ до $\mathrm{r}=0,28)$, но с показателями интереса к учебным предметам показатели школьной тревожности коррелируют обратной связью слабой силы (от $r=-0,10$ до $r=-0,21)$. Таким образом, ухудшение субъективного отношения к школьным предметам и увеличение трудности школьных предметов сопровождаются увеличением показателей школьной тревожности (коэффициенты прямой связи), тогда как росту интереса к предметам школьного обучения сопутствует уменьшение выраженности аспектов школьной тревожности (коэффициенты обратной связи).

При этом наиболее часто выявляются достоверные коэффициенты корреляции различных аспектов школьной тревожности с «прямыми» оценками трудности уроков в школе, несколько реже - с показателями интереса к урокам и субъективного отношения к ним. Среди последних чаще достоверными оказываются коэффициенты корреляции аспектов школьной тревожности с показателями суммы цветовой и ранговой компоненты ЦТО.

Наибольшее число достоверных корреляционных связей показателей ЦТО, трудности уроков и интереса к ним выявляется с такими аспектами школьной тревожности, как «фрустрация потребности в достижении успеха», «страх не соответствовать ожиданиям окружающих», «переживание социального стресса», несколько реже - с показателями «проблем и страхов в отношениях с учителями». Поскольку показатели школьной тревожности отражают степень психоэмоционального напряжения организма учащихся в процессе адаптации к школьному обучению [10], достоверные корреляции с ними показателей ЦТО и субъективных оценок трудности уроков и интереса к ним указывают на адекватность отражения этими показателями общей трудности учебного процесса для учащихся и подтверждают гигиеническую обоснованность их применения для ранжирования трудности учебных предметов.

Для обоснования формулы определения трудности учебных предметов по предложенным данным были проведены корреляционные взаимосвязи между ними показателями субъективного отношения к учебным предметам по ЦТО и «прямыми» оценками трудности уроков и интереса к ним. Полученные данные свидетельствуют о прямых корреляционных взаимосвязях между показателями подсознательной оценки эмоционального отношения к предметам по ЦТО и «прямыми» оценками трудности учебных предметов (от $r=0,13$ до $r=0,18)$, тогда как с оценками интереса к урокам эти же показатели коррелируют обратной связью (от $r=-0,12$ до $r=-0,29)$. Таким образом, показатели интереса к урокам снижают оценку трудности учебного предмета и улучшают его субъективную оценку по ЦТО, и в формуле общей трудности уроков должны иметь противоположный знак 
по отношению к показателям ЦТО и «прямой» оценке трудности урока. Поэтому предлагаемая формула определения общей трудности учебного предмета, по нашему мнению, может быть следующей: субъективное отношение к предмету (сумма баллов по ЦТО) + «прямая» оценка трудности - оценка интереса к предмету. На примере данных, представленных в таблице 1, индивидуальная оценка общей трудности урока русского (родного) языка для Виктории Е. будет равна $2(=6+1-5)$, а урока математики $-9(=8+4-$ 3). Ниже в таблице 3 представлены среднеарифметические значения со стандартной ошибкой $(\mathrm{M} \pm \mathrm{m})$ общей трудности основных учебных предметов (на примере 4-х классов), рассчитанных по предложенной формуле и переведенных в собственно баллы трудности предметов после оценки достоверности различий между ними и округления - для удобства применения в школьной практике при анализе и составлении учебных расписаний.

Таблица 3

Показатели общей трудности основных учебных предметов, преподаваемых в 4-х классах (в условных баллах)

\begin{tabular}{|l|c|c|}
\hline Учебные предметы & $\mathrm{M} \pm \mathrm{m}$ & Итоговая оценка трудности \\
\hline Русский (родной) язык & $6,51 \pm 0,28$ & 7 \\
\hline Литература (чтение) & $4,03 \pm 0,21$ & 6 \\
\hline Математика & $5,58 \pm 0,27$ & 4 \\
\hline Изобразительное искусство & $4,39 \pm 0,25$ & 5 \\
\hline Физическая культура & $4,94 \pm 0,28$ & 7 \\
\hline Иностранный язык & $6,63 \pm 0,37$ & 6 \\
\hline История & $5,68 \pm 0,37$ & 5 \\
\hline Природоведение & $4,84 \pm 0,28$ & 4 \\
\hline Труд (технология) & $4,17 \pm 0,23$ & \\
\hline
\end{tabular}

Из анализа данных таблицы 3 следует, что наиболее трудными предметами для учащихся 4-х классов являются родной и иностранный языки (по 7 баллов), далее идут математика и история (по 6 баллов), природоведение и физкультура (по 5 баллов), а наименее трудные - литература, изобразительное искусство и труд (по 4 балла); в целом это не противоречит данным других авторов [6; 7; 11], но, на наш взгляд, более адекватно отражает различия между учебными предметами по степени трудности и восприятию их учащимися.

На основании аналогичного анализа данных всех 1633 учащихся 1-11-х классов, принимавших участие в исследовании, нами была разработана и предложена новая шкала общей трудности учебных предметов, представленная в таблице 4.

Таблица 4

Показатели общей трудности основных учебных предметов, преподаваемых в 1-11-х классах (итоговые оценки в условных баллах) 


\begin{tabular}{|l|c|c|c|c|c|c|c|c|c|c|c|}
\hline \multirow{2}{*}{ Учебные предметы } & \multicolumn{10}{|c|}{ Классы } \\
\cline { 2 - 14 } & 1 & 2 & 3 & 4 & 5 & 6 & 7 & 8 & 9 & 10 & 11 \\
\hline Количество обследованных & 76 & 105 & 120 & 309 & 224 & 329 & 158 & 134 & 68 & 55 & 70 \\
\hline Русский (родной) язык & 6 & 6 & 7 & 7 & 7 & 7 & 7 & 9 & 9 & 9 & 10 \\
\hline Литература (чтение) & 7 & 4 & 5 & 4 & 6 & 6 & 7 & 7 & 8 & 7 & 8 \\
\hline Математика & 6 & 7 & 5 & 6 & 6 & 7 & 10 & 10 & 7 & 10 & 8 \\
\hline Изобразительное искусство & 5 & 5 & 4 & 4 & 5 & 5 & 6 & 6 & 6 & 4 & 5 \\
\hline Физическая культура & 6 & 6 & 5 & 5 & 5 & 6 & 6 & 6 & 4 & 6 & 5 \\
\hline Иностранный язык & & 7 & 8 & 7 & 8 & 7 & 8 & 7 & 9 & 8 & 9 \\
\hline История & & & & 5 & 8 & 8 & 10 & 8 & 9 & 8 & 9 \\
\hline География (природоведение) & & & 4 & 5 & 5 & 6 & 7 & 8 & 6 & 7 & 7 \\
\hline Биология & & & & & 6 & 6 & 5 & 6 & 6 & 5 & 7 \\
\hline Труд (технология) & 5 & 4 & 4 & 4 & 6 & 5 & 6 & 6 & 5 & 6 & 6 \\
\hline Физика & & & & & & & 9 & 9 & 10 & 12 & 12 \\
\hline Химия & & & & & & & 9 & 9 & 10 & 10 & 11 \\
\hline Информатика & & & & & 6 & 5 & 6 & 8 & 6 & 7 & 6 \\
\hline
\end{tabular}

Как видно из анализа данных таблицы 4, как и в шкалах трудности, предложенных другими авторами $[1 ; 3 ; 9]$, наиболее трудными школьными предметами остаются физика, химия, далее следуют математика и русский (родной) язык, за ними - история и иностранный язык. Наименее трудными, так же как и в других вариантах шкал трудности, остаются уроки изобразительного искусства, физической культуры и труда (технологии); остальные школьные предметы имеют промежуточные значения общей трудности, хотя в отдельных возрастных группах (классах) трудность этих предметов должна учитываться приоритетно (например, уроки литературы / чтения в 1-х классах).

Заключение. На наш взгляд, предложенная шкала трудности учебных предметов позволяет не только руководствоваться ею при составлении или анализе рациональности учебного расписания, но и прогнозировать предметы, с которыми в большей степени может быть связано формирование у обучающихся различных аспектов школьной тревожности. Это определяется выявленными достоверными взаимосвязями компонентов общей оценки трудности учебных предметов с показателями школьной тревожности. К тому же предложенная методика, прежде всего, учитывает субъективное восприятие учащимися сложности учебного предмета и их интереса к его содержанию. Не противореча в целом ранговым оценкам трудности учебных предметов других авторов, предложенный подход может быть использован при оценке новых предметов, вводимых в школьное обучение, позволяя провести условное ранжирование уроков в более короткие сроки без развертывания длительных и массовых сравнительных исследований умственной работоспособности в унифицированных условиях естественного гигиенического эксперимента. 


\section{Список литературы}

1. Александрова И.Э. О взаимосвязи показателей утомляемости учащихся с факторами урока и школьного расписания // Здоровье населения и среда обитания. 2017. №8(293). С. $24-$ 26.

2. Титова Ю.В., Транковская Л.В., Шепарев А.А., Нагирная Л.Н., Скварник В.В. Гигиеническая оценка трудности учебных предметов православного компонента общего образования // Современные проблемы науки и образования. 2014. № 6. [Электронный pecypc]. URL: https://www.science-education.ru/ru/article/view?id=16795 (дата обращения: 20.10.2018).

3. Харламов Е.В., Сидоренко Ю.А., Сависько А.А. Проблема адаптации к учебной нагрузке в системе непрерывного образования // Здоровье и образование в XXI веке: электронный сборник научных трудов. 2011. Т. 13. № 10. С. 481-482.

4. Степанова М.И., Александрова И.Э., Сазанюк 3.И. Гигиеническая регламентация использования электронных образовательных ресурсов в современной школе // Гигиена и санитария. 2015. № 7. С. 64-68.

5. Murnaghan D., Morrison W., Laurence C., Bell B. Investigating Mental Fitness and School Connectedness in Prince Edward Island and New Brunswick, Canada. Journal of School Health. 2014. Vol. 84. P. 444-450.

6. Александрова И.Э., Степанова М.И. Новая шкала трудности учебных предметов как инструмент гигиенической регламентации школьных нагрузок // Здоровье населения и среда обитания. 2003. № 9. С.21-25.

7. Анисимова Н.В., Монахова Н.Е., Савина Л.Н. Гигиеническая регламентация оценки школьного расписания уроков // Актуальные проблемы обучения физико-математическим и естественнонаучным дисциплинам в школе и вузе: материалы VI Межрегиональной научнопрактической конференции учителей, посвященной 75-летию Педагогического института имени В. Г. Белинского / Под общей редакцией М. А. Родионова. 2015. С. 252-257.

8. Бодалев А.А., Столин В.В. Общая психодиагностика: основы психодиагностики, немедицинской психотерапии и психологического консультирования. М., 1987. 304 с.

9. Столяренко Л.Д. Основы психологии. Практикум. Ростов-на-Дону: Феникс, 1999. $576 \mathrm{c}$.

10. Петунова С.А., Григорьева Н.В. Исследование учебного стресса школьников: причины, признаки, способы преодоления // Совершенствование системы высшего образования: опыт и перспективы: материалы VIII Международной учебно-методической конференции / Под редакцией А.Ю. Александрова, Е.Л. Николаева. 2016. С. 446-455. 
11. Мищенкова Е.В. Здоровьесберегающие технологии на уроках английского языка в начальной школе // Наука, техника и образование. 2015. № 3 (9). С. 59-60. 